\title{
A study of facial expression in Parkinson's disease using a novel microcomputer-based method
}

\author{
M KATSIKITIS, I PILOWSKY \\ From the University of Adelaide, Department of Psychiatry, Royal Adelaide Hospital, Adelaide, South Australia
}

SUMMARY The aim of this study was to compare the smiling behaviour of a group of Parkinson's disease sufferers with a control group of a similar age using a novel microcomputer-based approach, which utilises a mathematical model of the face to quantify facial expression. The findings indicate that the Parkinsons group differed from the control group in the frequency of smiling while watching a series of cartoons and in the degree of mouth opening during smiling. Both groups completed the Levine-Pilowsky Depression questionnaire, and patients with Parkinson's disease had significantly higher depression scores than those of the control group. Significant negative correlations between depression score and frequency of smiling, and depression score and inner eyebrow separation were also found.

The gradual loss of facial mobility and "mask-like" appearance seen in Parkinson's disease are well known. Rinn ${ }^{1}$ noted that these patients are able to move their facial muscles voluntarily, but are unable to react with spontaneous expressive gestures. Similarly Buck and Duffy ${ }^{2}$ found that Parkinsonian patients were rated as significantly less expressive than an aphasic and a control group, on a task designed to assess spontaneous facial expression. Although the high incidence of depression found in patients with Parkinson's disease ${ }^{34}$ may constitute a partial explanation for the psychomotor retardation and lack of spontaneity of facial expression, Rinn ${ }^{1}$ and Vogel $^{5}$ have shown that these characteristics are not simply due to depression, but are also found in nondepressed Parkinsonian patients.

The objective study of facial expression in Parkinson's disease has been difficult owing to the lack of a method for capturing and quantifying the relevant aspects of facial activity. A novel microcomputerbased approach, which uses a mathematical model of the face to quantify facial expressions has recently been developed. ${ }^{67}$ The aim of the present study was to examine aspects of smiling behaviour in Parkinson's disease using this technique.

Address for reprint requests: Professor I Pilowsky, The University of Adelaide, Department of Psychiatry, Royal Adelaide Hospital, Adelaide, South Australia, 5000.

Received 29 May 1987 and in revised form 29 September 1987. Accepted 1 October 1987

\section{Subjects}

The group studied was composed of nine patients (six males three females), eight with a diagnosis of idiopathic Parkin son's disease and one patient who was severely disabled witho Shy Drager Syndrome. All patients were attending the Royal Adelaide Hospital Parkinson's Review Clinic. Alb were members of the Parkinson's Syndrome Society of South Australia who had responded to an invitation to con tact the clinic if they wished to be involved in an intensive treatment programme, which included a neurological exam? ination, as well as participation in a specially designed programme of occupational therapy and physiotherapy. The neurologist informed each patient of the facial expression research project and asked for volunteers. The control group comprised of two males and seven females of comparable age who had no physical illness.

\section{Method}

All patients and controls completed the Levine-Pilowsky Depression (LPD) questionnaire, ${ }^{89}$ which provides a depression score between 1 and 20 for each subject, as well as a classification into one of three groups: non-endogenously depressed, endogenously depressed, and non-depressive. Subjects were seen individually, in a room which contained a slide projector, screen, stopwatch and two chairs facing a projector screen. Two wall mounted video cameras recorded each session. Each person was told that the project was designed to investigate the amount of movement in the face while viewing a series of amusing slides. One experimenter remained in the room to operate the equipment while the other recorded the session from an adjoining room. Eleven cartoon slides were each presented for 20 seconds. After each slide the subjects were asked to indicate how funny they 

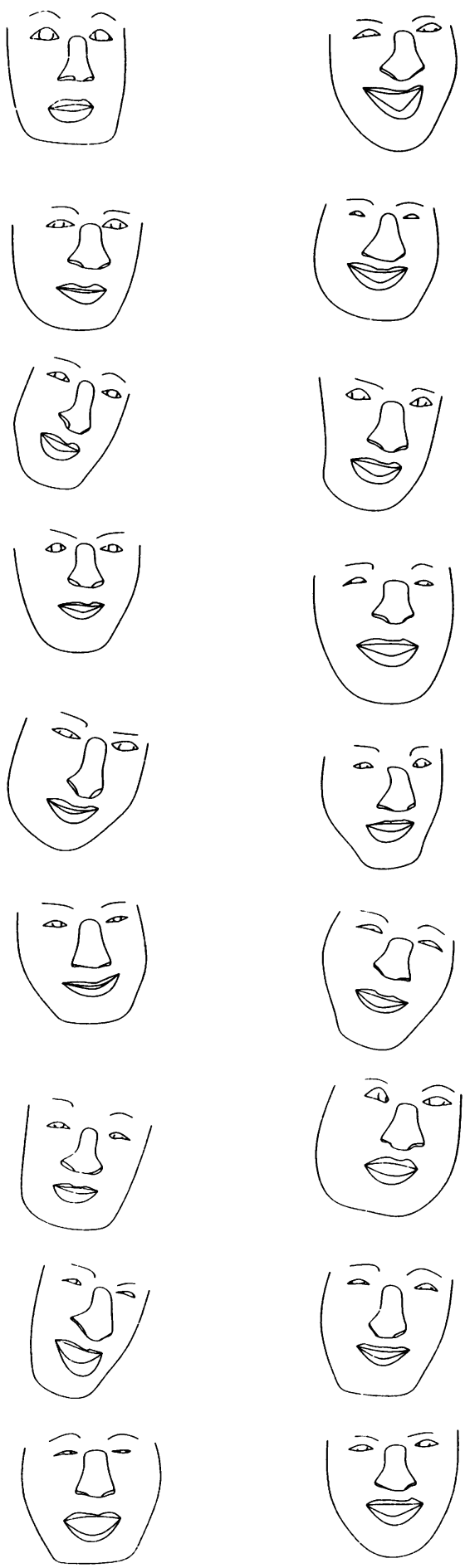

Parkinsonian group

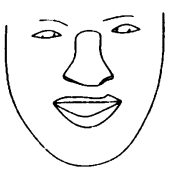

Control group

Fig 1 The facial outlines produced by the computer of the Parkinsonian group and the control group. thought the cartoon was on a four point scale ranging from "very funny" to "not at all funny".

Two judges viewed the videotape recordings of all sessions and selected the most animated smile of each subject for microcomputer analysis. A hard copy, that is, a still photograph of each person's smile was made from the videotape, using a Mitsubishi printer. These smiles were digitised according to a standard procedure ${ }^{7}$ and scores on 12 facial measures were obtained. The facial outlines produced by the computer using the mathematical model are shown in fig 1 .

The twelve measures are: end lip raise, mouth width, mouth opening, mid top lip raise, mid low lip raise, top lip thickness, lower lip thickness, eye opening, top eyelid/iris intersect, lower eyelid/iris intersect, inner eyebrow separation and mid eyebrow raise (figs 2,3 ). Each measure is standardised by being divided by one of two reference measures: the distance between the outer canthi of the eyes for "horizontal" measures and the length of the nose for "vertical" measures (fig 4).

\section{Results}

The length of illness in the Parkinson's disease group ranged from 3 to 12 years (mean $=7.3 \mathrm{yrs}$ ), with ages ranging from 50 to 74 years (mean $=63.7)$ and in the control group from 60 to 77 years (mean $=69 \cdot 2$ ). There were no significant age $(t=-1 \cdot 34, p=0 \cdot 20)$ or sex (Fisher's Exact Test, $p=0.08$ ) differences between the two groups. Eight of the Parkinsonian patients were on levodopa preparations taken three or four times daily for at least 12 months prior to the study with only one moderate case of on/off fluctuations observed. Seven patients were also taking medication related to their Parkinsonism, such as bromocriptine. Table 1 shows the clinical details available for each patient.

The Parkinsonian patients had higher depression scores (mean $=7.5)$ than the control group (mean $=2 \cdot 7$ ). The difference was highly significant (Mann-Whitney $U$ test, $p=0.008$ ). Although eight of

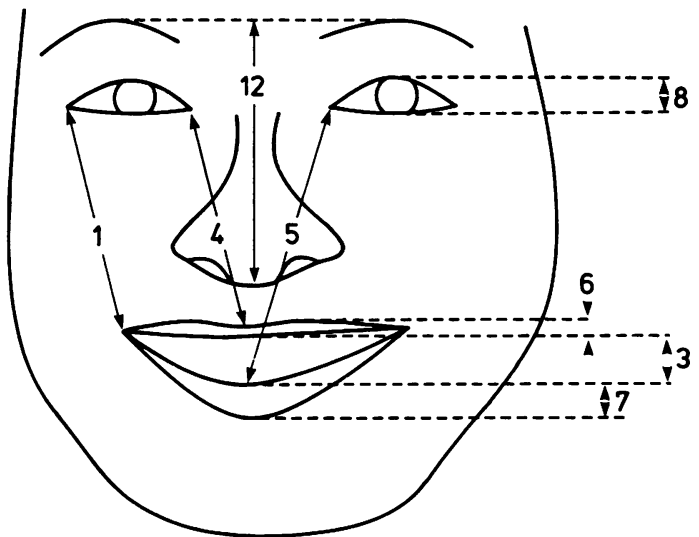

Fig 2 Vertical face measures. 1, 4, 5, 8 and 12 are measured on each side of the face and averaged. 


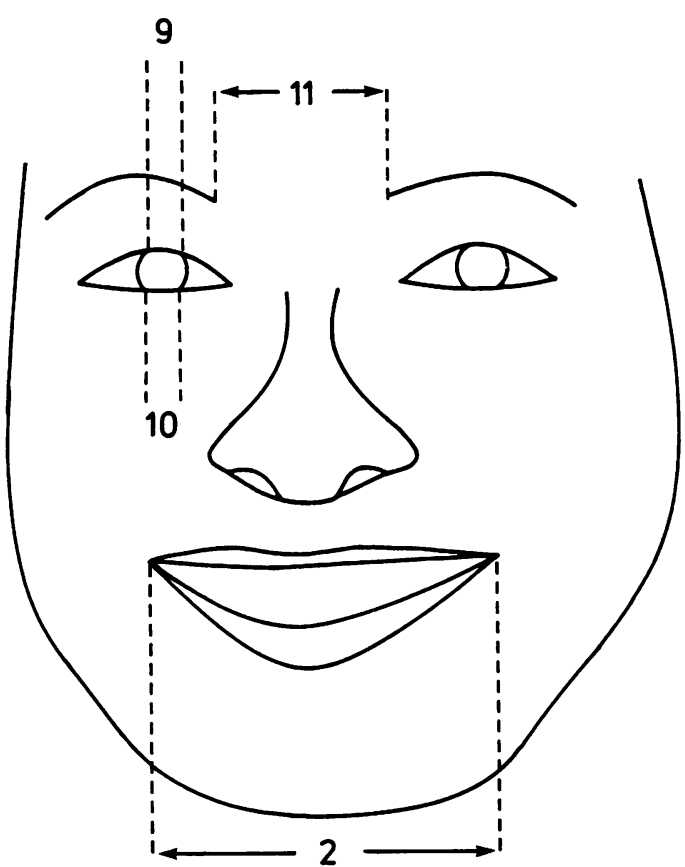

Fig 3 Horizontal face measures. 9 and 10 are measured on each side and averaged.

the nine Parkinsonian patients were classified as nondepressive that is, did not manifest a depressive syndrome on the LPD, their depression scores on a scale from one to twenty, fell into the "moderate range", whereas the control group had "mild" depression scores.

Two independent judges scored the frequency of smiling in the two groups from the videotapes made during the cartoon viewing sessions. Members of the

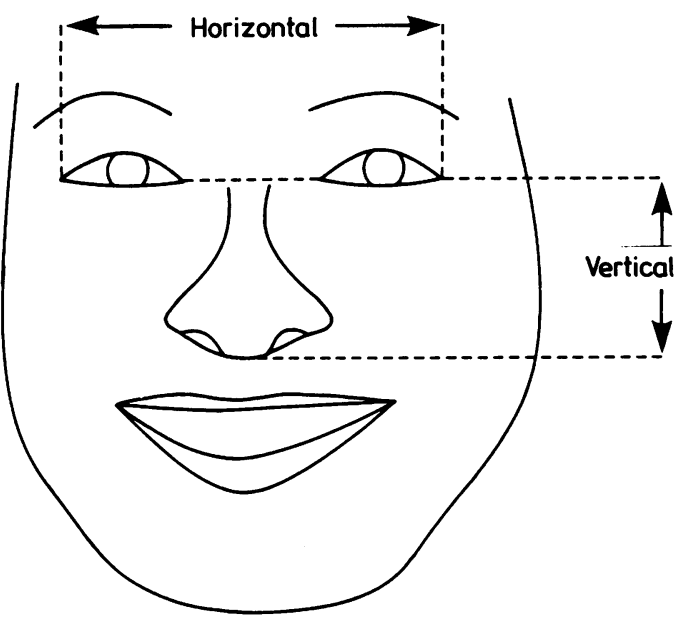

Fig 4 Reference measures.

control group were found to smile on average significantly more often while watching the cartoons than the Parkinsonian group (Mann-Whitney U Test, $p=0.002$ ). To ascertain whether the control group found the cartoons more amusing than the Parkinsonian group, an item analysis was performed on the ratings for each cartoon given by the subjects. Of the 11 cartoons, a significant difference emerged only on one cartoon, which the control group rated as significantly funnier than did the Parkinsonian group (Fisher's Exact Test, $p=0.03$ ). The frequency of smiling and the depression scores were correlated and a significant negative association emerged (rho $=-0.47, \mathrm{p}=0.028$ ) indicating that the frequency of smiling decreases as the depression score increases.

Table 2 shows the means and standard deviations

Table 1 Clinical and medication details for the Parkinsonian group

\begin{tabular}{|c|c|c|c|c|}
\hline $\begin{array}{l}\text { Patient } \\
\text { number }\end{array}$ & $\begin{array}{l}\text { Duration } \\
\text { of treatment } \\
(y r)\end{array}$ & $\begin{array}{l}\text { Levodopa dose (per day) } \\
+ \text { dopa decarboxylase } \\
\text { inhibitor }\end{array}$ & $\begin{array}{l}\text { Other } \\
\text { medication }\end{array}$ & $\begin{array}{l}\text { Clinical } \\
\text { status }\end{array}$ \\
\hline 1 & 7 & $\begin{array}{l}375 \text { mgm (with carbidopa) } \\
\text { in divided dose }\end{array}$ & $\begin{array}{l}\text { Bromocriptine } 5 \mathrm{mgm} / \text { day } \\
\text { Imipramine } 50 \mathrm{mgm} \text { nocte }\end{array}$ & $\begin{array}{l}\text { Mild. No significant daily } \\
\text { fluctuation }\end{array}$ \\
\hline 2 & 4 & $\begin{array}{l}800 \text { mgm (with benserazide) } \\
\text { in divided dose }\end{array}$ & No other drugs & $\begin{array}{l}\text { Mild disability without } \\
\text { fluctuation }\end{array}$ \\
\hline 3 & 8 & $\begin{array}{l}750 \text { mgm (with carbidopa) } \\
\text { in divided dose }\end{array}$ & $\begin{array}{l}\text { Bromocriptine } 10 \mathrm{mgm} / \text { day } \\
\text { Amantadine } 200 \mathrm{mgm} / \text { day }\end{array}$ & $\begin{array}{l}\text { Moderate disability with } \\
\text { fluctuation }\end{array}$ \\
\hline 4 & 3 & $\begin{array}{l}400 \text { mgm (with carbidopa) } \\
\text { in divided dose }\end{array}$ & Amantadine $200 \mathrm{mgm} / \mathrm{day}$ & $\begin{array}{l}\text { Mild disability without } \\
\text { fluctuation }\end{array}$ \\
\hline 5 & 9 & $\begin{array}{l}1,000 \text { mgm (with carbidopa) } \\
\text { in divided dose }\end{array}$ & No other drugs & $\begin{array}{l}\text { Moderate disability with } \\
\text { fluctuation }\end{array}$ \\
\hline 6 & 9 & $\begin{array}{l}150 \text { mgm (with benserazide) } \\
\text { in divided dose }\end{array}$ & Benztropine $6 \mathrm{mgm} /$ day & $\begin{array}{l}\text { Moderate disability } \\
\text { without fluctuation }\end{array}$ \\
\hline 7 & 4 & None & $\begin{array}{l}\text { Bromocriptine } 20 \mathrm{mgm} / \text { day } \\
\text { Amantadine } 200 \mathrm{mgm} / \text { day }\end{array}$ & $\begin{array}{l}\text { Mild disability without } \\
\text { fluctuation }\end{array}$ \\
\hline 8 & 5 (deceased) & $\begin{array}{l}400 \text { mgm (with carbidopa) } \\
\text { in divided dose }\end{array}$ & Bromocriptine $7.5 \mathrm{mgm} /$ day & $\begin{array}{l}\text { Shy Drager Syndrome } \\
\text { Severely disabled } \\
\text { Little fluctuation }\end{array}$ \\
\hline 9 & 12 & $\begin{array}{l}750 \text { mgm (with carbidopa) } \\
\text { in divided dose }\end{array}$ & Benzhexol $2 \mathrm{mgm}$ mane & $\begin{array}{l}\text { Mild disability } \\
\text { Without fluctuation }\end{array}$ \\
\hline
\end{tabular}


Table 2 Means and standard deviations for 12 facial measures in the Parkinsonian and Control groups

\begin{tabular}{|c|c|c|}
\hline Measures & $\begin{array}{l}\text { Parkinson's } \\
\text { disease patients }\end{array}$ & Control \\
\hline $\begin{array}{l}\text { End lip raise } \\
\text { Mouth width } \\
\text { Mouth opening } \\
\text { Mid top lip raise } \\
\text { Mid low lip raise } \\
\text { Top lip thickness } \\
\text { Low lip thickness } \\
\text { Eye opening } \\
\text { Top lid/iris intersect } \\
\text { Low lid/iris intersect } \\
\text { Inner eyebrow } \\
\text { Mid eyebrow raise }\end{array}$ & $\begin{array}{l}38.21(12.57) \\
42.50(13.41) \\
32.69(23.79) \\
48.42(17.18) \\
31.90(10.78) \\
58.97(13.66) \\
64.24(14.24) \\
53.46(15.59) \\
79.67(12.22) \\
67.70(17.85) \\
59.81(26.24) \\
23.04(19.58)\end{array}$ & $\begin{array}{l}30.57(12.31) \\
50.06(17.00) \\
44.36(12.25)^{*} \\
33.71(16.04) \\
31.56(8.66) \\
64.18(16.01) \\
58.63(14.44) \\
52.74(12.21) \\
80.79(10.70) \\
67.10(11.85) \\
60.31(16.49) \\
13.11(9.84)\end{array}$ \\
\hline
\end{tabular}

*p $<0.05$ (Mann Whitney U test).

of the 12 facial measures for the most animated smiles for each of the subjects in the Parkinsonian and control groups, which were selected as described earlier in the methodology section.

Of the differences between the three measures most pertinent to the smiling expression that is, end lip raise, mouth width and mouth opening, only the last of these reached significance, indicating that the Parkinsonian group did not open their mouths to the same degree during a smile as did the control group. No other facial measure distinguished significantly between the two groups. Inspection of the means in table 1 suggests that the difference was due to increased elevation of the upper lip in the controls, since the means of the "mid top lip raise" measures show a marked difference although it does not achieve statistical significance.

The 12 facial measures were correlated with the depression scores in the Parkinsonian group. Inner eyebrow separation, which is a measure of the distance between the inner eyebrows, was significantly negatively correlated with depression score $(r h o=0.708, p=0.025)$. This indicates that the eyebrows are drawn together as the depression score increases.

\section{Discussion}

These results demonstrate differences in both the frequency and degree of smiling between a group of Parkinsonian sufferers and controls. These differences cannot be attributed to a diminished appreciation of humorous cartoons in the Parkinson's disease group and must be considered a manifestation of the disease process and the associated depressive affect. It is interesting that the difference in smiling intensity seems to be due to a lack of responsiveness of muscles responsible for elevating the upper lip, such as levator labii superioris and zygomaticus minor. The reasons for this are not clear. However, the association between the depression score and movement of the inner eyebrow in the Parkinsonian group indicates the involvement of the corrugator muscle, which is entirely in accord with the findings of Schwartz et al, ${ }^{10}$ who have demonstrated, using electromyographic techniques, that changes in corrugator muscle tension level are a reliable indication of clinical improvement in depressed patients.

Given the salience of facial expressions, and in particular smiling, to the interpersonal communication of affect, the approach to quantification we have described, may assist in the planning and monitoring of physiotherapeutic or rehabilitation approaches aimed at improving the patients' capacity to communicate emotional states. When it is considered that the presentation of an expressionless face may inhibit the facial expression and emotional state of others, it is not inconceivable that an improvement in this regard may offset at least one of the interpersonal variables which contribute to the development of depression in Parkinson's disease.

The small number of patients studied, and the fact that they cannot be regarded as representative of Parkinsonian patients in general, indicate that our findings must be regarded as preliminary in nature. However, they do support the validity of the mathematical model of the face as a basis for studying facial activity and expression in conditions such as Parkinson's disease, where these functions are compromised.

The nature of the causal relationship between affect and facial expression in Parkinson's disease is clearly a complex one, deserving of further study. As a follow-up to this study, a further research project is currently being planned by one of the authors (M.K.), involving the comparison of a larger number of Parkinsonian sufferers with a matched sample of depressed patients as well as a control group on such measures as frequency and degree of smiling, degree of depression and quantifiable facial activity. Currently, however, the present study introduces a new technique with which to pursue and further elucidate the relationship between Parkinsonism, facial activity and depression.

The authors gratefully acknowledge the co-operation of Dr Don Burrow, Department of Neurology, Royal Adelaide Hospital, for his referral of the Parkinsonian patients to this study, and to Ms Cathy Wakelin, Occupational Therapy student, South Australian Institute of Technology, for her assistance in gathering the data for this project.

\section{References}

1 Rinn WE. The neuropsychology of facial expression: A review of the neurological and psychological mechanisms for producing facial expressions. Psychological Bulletin 1984;95:52-7. 
2 Buck R, Duffy RJ. Nonverbal communication of affect in brain-damaged patients. Cortex 1980;16:351-62.

3 Warburton JW. Depressive symptoms in parkinsonian patients referred for thalamotomy. J Neurol Neurosurg Psychiatry 1967;30:368-70.

4 Mindham RHS. Psychiatric symptoms on parkinsonism. J Neurol Neurosurg Psychiatry 1970;33:188-91.

5 Vogel HP. Symptoms of depression in Parkinson's disease. Pharmacopsychiatria 1982;15:192-96.

6 Thornton M, Pilowsky I. Facial expressions can be modelled mathematically. $\mathrm{Br} J$ Psychiatry 1982; 140:61-3.

7 Pilowsky I, Thornton M, Stokes B. A microcomputer based approach to the quantification of facial expressions. Australasian Physical and Engineering Sciences in Medicine 1985;8:70-5.

8 Pilowsky I, Levine S, Boulton DM. The classification of depression by numerical taxonomy. $\mathrm{Br} J$ Psychiatry 1969;115:937-45.

9 Pilowsky I, Spalding D. A method for measuring depression: Validity studies on a depression questionnaire. Br J Psychiatry 1972;122:411-6.

10 Schwartz GE, Fair PL, Mandel MR, Salt P, Mieske M, Klerman GL. Facial electromyography in the assessment of improvement in depression. Psychosom Med 1978;40:355-60. 